\title{
Da informalidade à formalidade: 0 percurso inicial da organização social da análise do comportamento*
}

\section{Informality to formality: The initial course of social organization of behavior analysis}

\author{
Robson Nascimento da Cruz ${ }^{1}$
}

[1] Universidade Federal de Minas Gerais (UFMG), Brasil | Título abreviado: Organização social da análise do comportamento | Endereço para correspondência: Robson Nascimento da Cruz. Rua Agenor Alves, 68. CEP: 31990-040. Belo Horizonte, MG | E-mail: robsonncruz@ig.com.br

\begin{abstract}
Resumo: Quando analisamos a história de uma ciência somente a partir de seus aspectos formais, muitas vezes desconsideramos que a organização da ciência depende de uma rede de relações sociais responsável por produzir e amparar sua aceitação e manutenção ao longo do tempo. No presente estudo, analisamos como tal rede se constituiu e contribuiu em parte da formação histórica inicial da análise do comportamento enquanto comunidade científica, emergente entre as décadas de 1930 e 1950, nos Estados Unidos. Esta investigação baseou-se no exame dos seguintes pontos: (a) o intenso contato informal entre B. F. Skinner e F. S. Keller, como primeiro passo para o estabelecimento institucional de uma nova ciência do comportamento; (b) a rejeição do delineamento experimental de sujeito único por parte significativa da psicologia experimental norte-americana, aliada às dificuldades de comunicação e ao isolamento entre os primeiros analistas do comportamento, como motivo para o início da organização social do campo; (c) a primeira conferência de análise experimental do comportamento, em 1947, como fonte de propagação de uma nova comunidade científica. O funcionamento social de uma nova ciência - por meio de uma rede de relações informais que resultou em sua crescente formalização, institucionalização, visibilidade e aceitação - é a principal conclusão derivada da presente investigação.
\end{abstract}

Palavras-chave: análise do comportamento, análise experimental do comportamento, história do behaviorismo, história da psicologia

\begin{abstract}
When we analyze the history of a science based in its formal aspects, we don't frequently take into account that the science organization depends on a social relation net responsible for the production and support of its acceptance and maintenance along the time. In this present study, we analyze the way this net was formed and was a responsible part for the initial historic formation of the behavior analysis as a scientific community, which emerges between the 1930s and the 1950s in the United States of America. This investigation had the following topics as basis: (a) the intense informal contact between B. F. Skinner and F. S. Keller, as a first step to the institutional establishment of a new behavior science; (b) the rejection of the experimental outlining of a unique subject, by a significant part of the north-american experimental psychology, and the communication difficulties and the isolation among the first behavior analysts, as reasons for the start of a social organization of the area; (c) the first conference of the experimental analysis of the behavior in 1947 as a spreading source of a new science community. The social organization of a new science - through a net of informal relationships that were born from its growing formalization, institutionalization, visibility and acceptance are the main conclusions derived from the present study.
\end{abstract}

Keywords: behavior analysis; experimental analysis of behavior; history of behaviorism, history of psychology 
A transformação de um pequeno grupo, orientado de maneira quase individual e relativamente desorganizada, em uma orientação coletiva e altamente organizada é uma das principais características da emergência da ciência moderna como uma complexa prática social em constante expansão, desde o seu surgimento, entre os séculos XVI e XVII (Meadows, 1999; Price, 1976; Rossi, 1989, 2001; Shapin \& Schaffer, 1985).

Este padrão de organização social da ciência seria identificado na instauração da primeira sociedade científica, a Royal Society of London, fundada em 1660 na Inglaterra. Por meio de correspondências e encontros informais, os membros daquela sociedade científica formaram uma rede de comunicação na qual cada um sabia o que estava sendo realizado pelos demais. Defender a prioridade de descobertas e invenções, manter em contato cientistas geograficamente dispersos e criar meios formais de divulgação e apoio da ciência foram suas principais funções (Meadows, 1999).

Embora atualmente seja indiscutível que a ciência representa uma complexa prática social, somente a partir da segunda metade do século XX esta concepção foi amplamente incorporada aos estudos históricos da ciência. Nesse contexto, o papel das relações informais entre os membros de uma comunidade científica já instituída, ou em formação, figura entre os elementos que começaram a ser tratados como relevantes para a compreensão do funcionamento social da ciência (Crane, 1972; Meadows, 1999; Menzel, 1966; Price \& Beaver, 1966; Swanson, 1966). A relevância dada ao caráter informal da ciência estaria sustentada pela concepção de que a informalidade seria um comportamento social anterior à própria formalização da ciência. A informalidade seria, portanto, parte constituinte da emergência e da manutenção da ciência (Crane, 1972; Price, 1976).

Como uma das maiores expressões do espaço de informalidade na ciência, Meadows (1999) destaca os encontros científicos. Para o autor, "os congressos e conferências são o protótipo da interação informal" (p. 139). Isso porque os participantes de um evento científico não vão a congressos apenas para apresentarem e assistirem a exposições de resultados de pesquisas, mas também para trocarem informações de ordem política, institucional, eco- nômica e social, além de estabelecerem negociações e acordos com pesquisadores distantes geograficamente. Outras situações também são descritas por Meadows como espaços de informalidade na ciência, como as bancas de mestrado e de doutorado e as comissões de avaliação científica. No presente, ainda poderíamos citar o aumento dessa informalidade por meio de mecanismos de comunicação como e-mails, listas de discussões na internet, rede sociais, blogs, entre outros espaços.

Ao voltarmos nossa atenção para os primórdios da análise do comportamento, enquanto uma comunidade científica que emerge nos Estados Unidos entre as décadas de 1930 e 1950, nota-se que os contatos informais entre B. F. Skinner (19041990) e F. S. Keller (1899-1996), assim como entre eles e os primeiros adeptos da análise experimental do comportamento ao longo desse período, sinalizam a formação de uma rede de relações informais, responsável por parte das estratégias de organização da estrutura comunitária de uma nova ciência do comportamento. A realização dos primeiros eventos científicos da área, a elaboração do primeiro boletim informativo, a criação de publicações especializadas e a inclusão da análise experimental do comportamento em cursos de graduação e de pós-graduação indicam o estabelecimento desta nova área do conhecimento. $\mathrm{O}$ que temos nesse momento histórico é a formação de uma nova comunidade científica, orientada por um modelo psicológico derivado das proposições expostas por Skinner em seu primeiro livro, The Behavior of Organisms: An Experimental Analysis, publicado em 1938.

Todavia, é interessante notar que muitas dessas primeiras estratégias de organização social da análise do comportamento resultaram, como veremos adiante, da resistência ao método de pesquisa desta nova ciência no contexto da psicologia experimental norte-americana: o delineamento experimental de sujeito único. Método esse que, entre outras coisas, não recorrerá à estatística inferencial nem a grupos-controle - procedimentos prevalentes nos Estados Unidos entre as décadas de 1930 e 1950, tidos como indispensáveis em qualquer delineamento de pesquisa em psicologia experimental. A esse respeito, Rucci e Tweney (1980) ressaltam o modo pelo qual a adoção de técnicas como a análise de variância torna-se hegemônica na psicologia 
experimental norte-americana entre 1930 e 1950. Hegemonia observada nos relatos de pesquisas veiculados nos principais periódicos da área, os quais incluíam métodos estatísticos e grupos-controle com elevado número de sujeitos experimentais entre os critérios presentes em suas políticas editoriais (Harlow, 1951). Além disso, observa-se que a maioria dos programas de pós-graduação em psicologia, no início da década de 1950, apresentavam disciplinas obrigatórias sobre análises estatísticas. Juntos, esses fatos sinalizavam a institucionalização de métodos estatísticos, tornando-os comuns e potencialmente necessários em toda pesquisa em psicologia experimental (Rucci \& Tweney, 1980).

Esta breve caracterização das pesquisas em psicologia experimental nos Estados Unidos, a partir da década de 1930, sugere que o delineamento experimental de sujeito único mostra-se incompatível com a supremacia de técnicas estatísticas (e.g., análise de variância). Não por acaso, uma das principais críticas endereçadas a Skinner, ao publicar The Behavior of Organisms, diz respeito à não utilização de grupos-controle e à ausência de tratamento estatístico dos dados (Skinner, 1979). Crítica essa estendida aos primeiros adeptos da análise do comportamento, quando esses começaram a tentar publicar seus relatos de pesquisas em meados da década de 1940. Naquele momento, a recepção negativa da análise do comportamento se torna um dos principais motivos, senão o principal, que levaram os primeiros psicólogos interessados nesta nova perspectiva a colocar em prática alguns mecanismos de organização social da ciência.

Tendo em vista este fato, argumenta-se no presente trabalho que a emergência histórica da análise do comportamento não segue a premissa muitas vezes ensinada de forma acrítica na pedagogia científi$\mathrm{ca}$, de que a existência de uma ciência seria produto exclusivo da validade interna do sistema científico que a sustenta, como se esta fosse suficiente para garantir sua aceitação e sobrevivência ao longo do tempo (Kuhn, 1962/2006). Em outras palavras, o presente trabalho expõe uma visão histórica do surgimento da análise do comportamento, na qual a organização social dessa ciência é inserida como elemento necessário e, em alguma medida, anterior à própria possibilidade de emergência e de existência de uma ciência pautada no sistema científico Skinneriano.
Esta visão da história da análise do comportamento apresenta-se como complementar aos estudos conceituais dessa disciplina, porque provê uma análise orientada para a compreensão dos efeitos de elementos extrateóricos na composição histórica de tal ciência. Assim, para compreendermos como a emergência histórica da análise do comportamento também pode ser vista sob o prisma de sua organização social, analisamos: (a) o papel de F. S. Keller como o primeiro interlocutor e apoiador informal de Skinner e como o principal porta-voz do sistema explicativo Skinneriano; (b) as dificuldades de aceitação das pesquisas baseadas nessa ciência e as dificuldades de comunicação entre os primeiros psicólogos interessados pela análise experimental do comportamento, como propulsoras da organização social dessa ciência; (c) a primeira conferência de análise experimental do comportamento, como a tentativa inaugural de formalização de uma nova comunidade científica e como um protótipo da interação informal na ciência.

\section{A Germinação de uma Nova Comunidade Científica: O Contato Informal entre B. F. Skinner e F. S. Keller}

Ainda que as bases do sistema explicativo Skinneriano já estivessem estabelecidas na segunda metade da década de 1930, é a partir de meados da década de 1940 que outros psicólogos experimentais começam a realizar pesquisas fundamentadas neste novo modelo psicológico (Skinner, 1979, 1984). Durante a segunda metade da década de 1930 e o início da década de 1940, Skinner (1979) revela ter enfrentado inúmeras dificuldades para dar continuidade ao projeto de desenvolvimento de uma ciência do comportamento. Dificuldades que tiveram início após o término de sua última bolsa de pós-doutorado em Harvard, em 1935, e o início da carreira como professor de psicologia na Universidade de Minnesota, entre 1936 e 1945. Nesse período, Skinner (1979) afirma ter sido muitas vezes impedido de divulgar e de realizar pesquisas que recorriam ao seu método de investigação científica: o delineamento experimental de sujeito único. Skinner também refere ter sofrido represálias por assumir uma posição teórica e metodológica diversa da aceita e ensinada em Minnesota e hegemônica na psicologia experimental norte-ame- 
ricana. Além disso, confessa ter se sentido isolado geograficamente, deparando com obstáculos para participar de importantes eventos científicos e para estreitar o contato com pesquisadores que pudessem ter interesse pelo seu trabalho (Skinner, 1979).

Em 1938, a publicação do livro The Behavior of Organisms: An Experimental Analysis sintetiza o primeiro empenho de Skinner para a formalização do seu programa de pesquisa durante a segunda metade da década de 1930. No entanto, Skinner (1979) recorda que o livro não provocou o impacto esperado por ele até o final da Segunda Guerra Mundial (1939-1945). Na época, somente Keller estava trabalhando com seus achados. Graças às investidas deste pesquisador na Universidade de Columbia, a partir do final da década de 1930 e durante a década de 1940, as vendas e o reconhecimento do primeiro livro de Skinner foram alavancados, garantindo a base inicial para o ensino de análise experimental do comportamento. Para uma análise detalhada da recepção inicial da analise experimental do comportamento e das condições institucionais de Skinner na década de 1930, ver Cruz (2011).

Contudo, antes do estabelecimento desses mecanismos formais de institucionalização da ciência, pode-se dizer que a germinação da organização social da análise do comportamento remonta ao final da década de 1920, devido ao intenso contato informal entre Keller e Skinner, quando ambos cursavam o doutorado de psicologia em Harvard. Sobre essa fase, tanto Skinner (1979) quanto Keller (2009) lembram que, provavelmente, eles eram os únicos alunos atraídos por uma perspectiva behaviorista naquela instituição. Ainda sobre esse período, Skinner (1979) recorda que Keller foi o principal e talvez o único interlocutor behaviorista durante o período de elaboração inicial de sua ciência do comportamento. Esse contato seria intenso durante toda a década de 1930 e o início da década de 1940, concretizado por meio de encontros e pela troca de correspondências.

Mais do que apoiar as formulações de Skinner naquele período, Keller irá declarar, após a leitura de The Behavior of Organisms, ser o primeiro adepto de sua ciência (Keller, 2009). Além da adesão ao modelo científico Skinneriano, no final da década de 1930, o papel de Keller na disseminação da nova ciência do comportamento torna-se evidente com a sua contratação para o Departamento de Psicologia da Universidade de Columbia. Instituição esta que, segundo ele, propiciou ótimas condições para que se dedicasse cada vez mais à pesquisa e ao ensino da análise do comportamento (Keller, 2009; Keller \& Schoenfeld, 1949). Ainda acerca disso, Keller (2009) informa que assumiu o posto de professor em Columbia com o objetivo imediato de iniciar pesquisas sobre o condicionamento operante. Contudo, mesmo com as boas condições de trabalho, o ambiente em Columbia inicialmente não foi favorável à sua empreitada behaviorista. Primeiro, porque "não havia nenhum verdadeiro behaviorista em Columbia em 1938, até mesmo no segundo andar entre os ratos e macacos" (p. 162). Segundo, porque ele experimentou, no final da década de 1930, a indisposição de alguns dos membros do Departamento de Psicologia para iniciar pesquisas que recorriam à nova abordagem psicológica (Keller, 2009).

No entanto, a partir da descrição da primeira pesquisa baseada nas formulações apresentadas em The Behavior of Organisms, nota-se que os empecilhos sofridos por Keller não o impediram de iniciar suas investigações baseadas no sistema científico presente naquele livro - ainda que para isso fosse preciso realizar os experimentos iniciais fora do contexto institucional da Universidade de Columbia. Deste modo, Keller (2009) descreve que sua primeira pesquisa inspirada em The Behavior of Organisms foi realizada em seu apartamento, tendo sua filha como participante. Segundo Skinner (1984), é provável que esse experimento tenha sido a primeira tentativa de uma análise experimental do comportamento humano. Tal episódio é descrito por Keller (2009) nos seguintes termos:

Uma tentativa inicial de pesquisa ocorreu em nosso apartamento, com Anne como meu sujeito experimental. Eu levei meu equipamento para casa e coloquei-o sobre a mesa da sala de jantar, próximo à porta corrediça que se abria para a sala de estar. Por meio de uma estreita abertura por entre a porta, preparei uma extensão da alavanca na sala de estar e afixei um tubo que descia para uma pequena vasilha sob a barra da alavanca. Isto me permitia jogar um pedaço de biscoito ou doce na vasilha sempre que a barra era pressionada, e a resposta era registrada no meu gravador.

Após me atrapalhar com o procedimento por 
um tempo, coletei dados sobre o efeito de vários procedimentos que tinham sido usados efetivamente em ratos. A pressão condicionada da alavanca foi estabelecida com biscoitos em formato de animais e pedaços de chocolates como recompensas (tecnicamente, reforçadores); um teste de extinção foi realizado por descontinuidade do reforço; um recondicionamento aconteceu pelo restabelecimento do reforço; e dados de reforços periódicos foram coletados por meio de recompensa por certo número de respostas ou após certos intervalos de respostas. (p. 165)

Em tom bem-humorado, Keller (2009) chegou a afirmar que havia ficado evidente a possibilidade de estudos de pressão à barra serem conduzidos em casa, inclusive levando-o a apresentar os resultados desse experimento em um evento científico. Entretanto, essa situação foi tomada como temporária e insatisfatória, porque seu objetivo era estudar o comportamento operante em laboratório sob condições adequadas. Isso, porém, Keller conseguiria apenas de maneira gradual, em Columbia, a partir do começo da década de 1940, quando ele inicia as primeiras pesquisas naquela instituição, fundamentadas em The Behavior of Organisms, enquanto simultaneamente introduzia o conteúdo do livro em suas aulas na graduação.

Contudo, mesmo começando a abrir espaço para realizar pesquisas e ensinar análise experimental do comportamento em Columbia, Keller ainda dizia estar insatisfeito com sua condição institucional, porque até então não lhe era permitido ter orientandos de mestrado e de doutorado - fato lembrado por ele como frustrante, tendo em vista a existência de alunos com desejo de realizar pesquisas na área. De acordo com Keller (2009), tal demanda aumentou gradativamente em função não só do ensino da nova abordagem psicológica na graduação em Columbia, mas também por causa da divulgação, muitas vezes informal, de experimentos envolvendo os métodos apresentados em The Behavior of Organisms.

A passagem a seguir, um registro do conteúdo de uma correspondência enviada a Skinner no começo da década de 1940, mostra como ainda existiam entraves institucionais em Columbia, os quais impediam Keller de orientar pesquisas baseadas no sistema explicativo Skinneriano e como, naquele momento, ele ainda recorria à informalidade para divulgar a nova abordagem psicológica na comunidade científica.

Eu escrevi a Burrhus, dizendo que havia vários alunos de pós-graduação que gostariam de desenvolver estudos de condicionamento, mas que me evitavam por causa de C. J., e que eu não tinha recebido patrocínio de pesquisa de doutorado, que forneceria um precedente a eles. De fato, meu estudante de mestrado (Hyman) está um pouco assustado em trabalhar comigo e fará o que puder para colocar um (Gordon) Allport ou (Gardner) Murphy em conformidade com seus resultados.

Em 06 de dezembro de 1941, eu falei informalmente sobre minhas descobertas da luz de aversão, em uma Mesa Redonda de Psicologia (MRP), em Massachusetts. A adesão à MRP era restrita aos experimentalistas com 40 anos ou que fossem mais jovens, e eu estava com quase 43, mas compareci como convidado de John e Dick, ambos já membros. (p. 169)

Ainda sobre o contato inicial estabelecido com Keller, é representativa da situação da análise do comportamento, naquela ocasião, a alegação de Skinner (1979) de que, além de Keller ser o único psicólogo durante muito tempo a aderir à sua proposta de uma ciência do comportamento, este muitas vezes se mostrou mais otimista do que ele próprio com aquele empreendimento científico.

Keller é o primeiro psicólogo experimental a estabelecer um alto grau de contato informal com Skinner - o que se deu, conforme mencionado, ainda no período de seu doutorado e o de Skinner, no final da década de 1920, em Harvard. No entanto, seu papel vai além de um apoiador informal, porque ele também empreendeu inúmeras estratégias que levaram à institucionalização e, por sua vez, à formalização da análise do comportamento. Sua participação direta na organização do primeiro currículo de psicologia fundamentado no sistema científico Skinneriano (Keller \& Schoenfeld, 1949), em 1946, e a publicação, em 1950, do primeiro livro-texto de psicologia também baseado nesta ciência, Principles of Psychology: A Systematic Text in the Science of Behavior (Keller \& Schoenfeld, 1950), estão entre as principais atividades empreendidas em Columbia, contribuindo para a disseminação daquela nova ciência do comportamento. Por isso, 
tendo em vista a contínua participação de Keller em outras inúmeras estratégias de disseminação da análise do comportamento ao longo de toda a sua carreira, não seria exagero afirmar que Keller se torna um dos principais - senão o principal - disseminadores do pensamento de Skinner nos Estados Unidos e em outros vários países, como no próprio Brasil (Keller, 2009). Apesar de não detalharmos neste trabalho os demais empreendimentos de Keller para a disseminação da análise do comportamento, o que se pretende destacar aqui é seu papel inicial como apoiador informal das proposições de Skinner (1979) e como o primeiro adepto daquele sistema científico ainda em formação.

\section{A Rejeição como Mola Propulsora da Organização Social da Análise do Comportamento}

A despeito de Keller realizar pesquisas que tiveram como base o sistema explicativo Skinneriano e de começar a divulgá-las a partir do final da década de 1930 e o início da década de 1940, somente ao final da Segunda Guerra Mundial as pesquisas começaram a ser realizadas de modo a assegurar visibilidade àquele grupo inicial de pesquisadores interessados nos conceitos e métodos apresentados em The Behavior of Organisms. Em meados da década de 1940, Skinner (1979) lembra que tais pesquisas estavam sendo realizadas em Columbia, "onde o rato era o principal sujeito experimental, e em Indiana, onde o pombo era o rei (p. 330)". Universidades nas quais, respectivamente, ele e Keller atuavam naquele período, tendo obtido condições institucionais para tanto.

Para Skinner (1979), porém, isso não era suficiente nem significava que seu sistema explicativo havia alcançado o reconhecimento por ele almejado. Na avaliação dele, entre a segunda metade da década de 1930 e o final da Segunda Guerra Mundial, poucos pesquisadores tinham se interessado por suas ideias, algo refletido na baixa vendagem de The Behavior of Organisms, após quase uma década de sua publicação. Ademais, Skinner sublinha que o pequeno grupo de pesquisadores adeptos de seu modelo científico, a partir da segunda metade da década de 1940, sofria contínuas dificuldades para publicar pesquisas que recorriam ao delineamento experimental de sujeito único. A rejeição de artigos pelas principais revistas de psicologia experimental norte-americanas e a insatisfação com o lugar que os trabalhos da área ocupavam em eventos científicos são citadas por Skinner como fatos representativos dessa situação desconfortável. Sobre esses problemas, ele descreve:

Tivemos dificuldades em publicar nossos relatórios em periódicos comuns. Nós utilizávamos um número muito pequeno de sujeitos, nós não "projetávamos nossos experimentos" com grupos comparativos, nossos registros cumulativos não se pareciam com curvas de aprendizado, e nós estávamos fazendo perguntas (por exemplo, sobre programas de reforçamento) que não eram encontradas na "literatura". Nas reuniões, nossos artigos eram misturados a outros que nós raramente queríamos conhecer. (Skinner, 1979, p. 330)

Este e outros relatos (Bjork, 1993; Dews, 1987; Dinsmoor, 1987; Kelleher \& Morse, 1987; Laties, 1987; Lindsley, 1987; Skinner, 1984) sobre a história da organização social da análise do comportamento expõem que as dificuldades em publicar pesquisas estavam relacionadas ao fato já mencionado de que o delineamento experimental de sujeito único era um procedimento estranho à psicologia experimental norte-americana. Em tais relatos também são expressas alegações de que as dificuldades iniciais de aceitação do delineamento experimental de sujeito único foram fator determinante para que surgissem meios de organização social dessa ciência, como a criação de uma publicação especializada. Mas, antes da criação dessa primeira publicação - o Journal of Experimental Analysis of Behavior (JEAB) -, ocorrida apenas em 1958, Skinner, Keller e Schoenfeld organizam, em 1947, como "uma solução temporária" (Skinner, 1979, p. 330) aos problemas de aceitação dos relatos de suas pesquisas e ao isolamento que havia entre eles, a primeira conferência de análise experimental do comportamento.

A seguir, discutiremos a proposta deste evento, os motivos (além dos já expostos) que levaram à sua organização e algumas consequências dessa conferência que expõe o papel crucial da informalidade como parte do trabalho de emergência e estabilização de uma nova ciência do comportamento.

\section{A Primeira Conferência de Análise Experimental do Comportamento e a Busca}




\section{por Visibilidade de uma Nova Ciência}

Tanto Keller, em Columbia, quanto Skinner, em Indiana, relatam que havia estudantes interessados em realizar pesquisas com base na nova perspectiva teórica e metodológica, mas que tais estudantes não tinham como reforçarem uns aos outros (Bjork, 1993; Keller, 2009; Skinner, 1979). Para eles, essa situação indicava a necessidade de criar um espaço de troca de informações entre os primeiros interessados naquela nova perspectiva psicológica. Necessidade que, segundo Bjork (1993), ocorre em função de um "sentimento de isolamento" (p. 143), já citado por Skinner (1979) e Keller (2009). Nesse sentido, a realização de um evento científico seria o meio pelo qual os problemas de aceitação e de isolamento poderiam, simultaneamente, ser amenizados.

Tal evento foi realizado na Universidade de Indiana, em 1947, onde Skinner havia assumido, há pouco mais de um ano, a chefia do Departamento de Psicologia. Informação relevante porque, conforme mencionado antes, Skinner já havia sido parcialmente impedido de divulgar sua ciência do comportamento em Minnesota. Já em Indiana, ele novamente passou a dispor de condições para continuar suas pesquisas e divulgar sua ciência, sem medo de represálias e dos demais controles institucionais. Ao relatar as condições de trabalho em Minnesota e prever as possíveis vantagens de se transferir para Indiana, Skinner (1979) afirma que sua posição nesta universidade lhe propiciaria maior valor e outras oportunidades profissionais. A retomada de contatos com inúmeros pesquisadores do quais ele havia se distanciado durante sua passagem por Minnesota e a construção de um laboratório estruturado somente para a realização de pesquisas envolvendo o seu método de pesquisa são algumas das provas de que sua previsão estava correta. Skinner (1979) relata ainda que, nessa nova instituição, poderia ter seus próprios alunos de pós-graduação, obter financiamentos e infraestrutura para realização de eventos científicos, como a primeira conferência de análise experimental do comportamento, organizada por ele e realizada em Indiana.

Sobre a caracterização dessa conferência, nota-se, em primeiro lugar, por parte de Skinner (1979), a importância dada à informalidade desse evento e sua função na construção inicial de uma definição geral de sua abordagem psicológica. Tais aspectos são percebidos quando ele afirma:

A reunião foi informal. Nós simplesmente escolhemos diferentes tópicos e falamos de onde estávamos, quando tínhamos algo a dizer. Nós a chamamos de conferência sobre a "análise experimental do comportamento", tomando a "análise experimental" do subtítulo de The Behavior of Organisms. (Skinner, 1979, p. 331)

O evento, porém, não tinha como função apenas ser um espaço de discussão para os pesquisadores que não estavam conseguindo publicar suas pesquisas e tinham dificuldades de estabelecer contato uns com os outros. Era, sobretudo, um momento de demarcar a identidade daquela nova ciência do comportamento. Isso fica claro quando Skinner (1979) expressa sua preocupação com o nome pelo qual aquele novo grupo deveria ser chamado: "Como deveríamos nos chamar? 'Estudantes do comportamento'? 'Analistas do Comportamento'? E quais adjetivos deveríamos utilizar para identificar nossa pesquisa, nossa teoria, ou nossa organização? 'Behaviorismo,' 'Behavioristas', isso era algo que não estava certo”. (p. 331)

Naquele momento, é também no mínimo curioso verificar que Skinner, mesmo sem dar explicação clara, questiona-se sobre o uso da denominação análise experimental. Para ele, esta expressão não parecia adequada para identificar o novo grupo científico na psicologia. Nas palavras de Skinner (1979), "este não era um nome totalmente satisfatório para um campo" (p. 331). Ainda mais surpreendente é observar que Skinner (1979) apresenta certa ressalva com relação ao fato de eles serem denominados behavioristas. Isso porque, segundo ele, para a maioria das pessoas ser behaviorista implicava identificar-se com as polêmicas que envolviam o behaviorismo de Watson. Esta era uma conotação que deveria ser evitada porque, como psicólogo, Skinner estava preocupado em estudar o comportamento e, segundo ele, isto não o tornava "necessariamente um behaviorista" (Skinner, 1979, p. 331). Exceto por esse motivo, ele não aponta outra razões para essa negação inicial de identidade com o behaviorismo.

Entretanto, se voltarmos à sua produção científica no período em questão, encontramos ao menos um motivo para tal negação: em meados da década de 1940, Skinner expõe, pela primeira vez, sua posição ao tratamento até então conferido aos eventos privados, diferenciando sua versão behaviorista 
das demais abordagens herdeiras dessa tradição. No conhecido artigo em que essa discussão emerge, "The Operational Analysis of Psychological Terms" (1945), Skinner discute a influência do operacionismo na psicologia norte-americana e afirma que "o behaviorismo tem sido (pelo menos para a maioria dos behavioristas) nada mais que uma análise operacional rigorosa de conceitos mentalistas tradicionais" (Skinner, 1945, p. 272). Mesmo discordando da crítica de psicólogos como Stevens e Boring, segundo a qual o behaviorismo era uma ciência primitiva, e advertindo que tais autores desconsideravam que behavioristas como Watson, Weiss, Tolman, Hunter, Lashley, entre outros, haviam formulado sofisticadas análises operacionais de termos psicológicos, Skinner reconheceu que "o behaviorismo também não chegou a uma contribuição positiva decisiva - e pela mesma razão: nunca completou uma formulação aceitável do 'relato verbal'. A concepção de comportamento que o Behaviorismo desenvolveu não pôde abranger convincentemente o 'uso de termos subjetivos"' (Skinner, 1945, p. 272).

O fato é que, como sabemos, historicamente a ressalva quanto a ser denominado de behaviorista não afetou a identificação de Skinner e daqueles adeptos de seu pensamento. Mas, por certo, já mostra certa consciência de Skinner de como sua ciência divergia em pontos cruciais das demais tendências behavioristas. E, mais do que isso, sua ressalva inicial não se mostrou injustificada, tendo em vista que a identificação de seu pensamento com a tradição behaviorista o levou a ser, inúmeras vezes, inserido em controvérsias como aquelas que começaram a ser recorrentes, em especial a partir da década de 1970, em várias partes do mundo (Cruz, 2010; Rutherford, 2000, 2003, 2004). De tal modo, afirmações como as de Chiesa (1994) - de que a identificação do behaviorismo radical com a tradição behaviorista, por mais redundante que isso possa parecer, representa um erro histórico - denotam como a preocupação inicial de Skinner com a denominação daquela nova comunidade científica adepta de sua abordagem não fora completamente descabida.

Ainda sobre a caracterização da primeira conferência de análise experimental do comportamento e a identidade do grupo inicial que constituiria a base para a formação de uma nova comunidade científica, outro participante desse evento, James A.
Dinsmoor (1921-2005) registra sua percepção acerca dos participantes daquele evento. Diz ele:

Nós dificilmente teríamos qualificado como um grupo "eclético" - nós certamente nos orgulhávamos do nosso rigor científico e, na maioria dos casos, nosso pensamento ficava mais próximo daquele de Skinner do que de outros teóricos -, mas nós não estávamos cegos.

(Dinsmoor, 1987, p. 443)

Dinsmoor (1987) afirma que eles não estavam cegos porque, além de Skinner, outros pesquisadores, como Hull e Kantor, eram discutidos em Columbia e também entre vários dos psicólogos que participaram daquela primeira conferência de análise experimental do comportamento. Segundo Dinsmoor, iniciou-se a partir de então um esforço de identificação do grupo participante da conferência com aquela nova explicação do comportamento, exposta em The Behavior of Organisms. As iniciativas de Keller e Schoenfeld, que já haviam criado um currículo de psicologia em Columbia fundamentado no sistema explicativo Skinneriano (Keller \& Schoenfeld, 1949) e naquele período estavam trabalhando na construção do primeiro livro-texto de psicologia também baseado nessa ciência, seriam também exemplo dessa busca por fortalecimento da identidade da área. No entanto, Dinsmoor afirma não se lembrar de qualquer imposição ortodoxa naquele momento senão a adesão a princípios científicos, ressaltando que a figura de Skinner foi dominante na conferência e que ele havia sido o participante mais ativo, sendo evidente seu esforço para apresentar os resultados de suas pesquisas e as definições básicas de seu sistema explicativo. Contudo, sublinha Dinsmoor, ainda que o trabalho de Skinner já fosse relativamente conhecido, este reconhecimento estava longe daquele que aconteceria nas décadas de 1970 e 1980.

A respeito dos temas abordados na conferência, Dinsmoor (1987) cita trabalhos que versaram sobre a definição de reforçamento negativo, o efeito do emparelhamento de estímulos (e.g., som e alimento) sobre o comportamento de pressionar a barra, entre outros. $\mathrm{O}$ autor também destaca a apresentação de resultados de pesquisas envolvendo seres humanos. Entre essas pesquisas, menciona um trabalho de Schoenfeld que lidava com os efeitos de reforço e punição com o uso das palavras certo e errado em 
um experimento sobre conformidade grupal, além do trabalho de Kay Estes envolvendo o reforçamento de emissão de palavras por estudantes da pré-escola.

Sobre a percepção que se obteve do evento e de suas prováveis consequências futuras, Dinsmoor (1987), a exemplo de Skinner (1984), ressalta o clima de informalidade durante a conferência e a formação de um grupo com objetivos amplos, fundamentados no sistema explicativo Skinneriano. A respeito disso, o autor ainda acrescenta:

Pode ser que tenhamos sido ingênuos em nosso otimismo sobre o futuro, mas muito do nosso entusiasmo vinha do fato de que nós estávamos enfrentando os mais amplos e os mais básicos problemas, assim como os percebíamos, de uma ciência sistemática do comportamento. (Dinsmoor, 1987, p. 444)

Na passagem a seguir, Keller (2009) ao recorda também da conferência descreve sua percepção sobre o evento e as estratégias de ensino de análise experimental do comportamento desenvolvidas por ele e por Schoenfeld em Columbia, enfatizando igualmente o papel da informalidade naquela ocasião e seu valor na formação inicial de uma nova comunidade científica.

Foi uma confraternização estimulante, uma das melhores das quais já participei. Nós conversamos sobre os experimentos feitos, os que estavam em progresso ou simplesmente planejados sobre condicionamento, discriminação, motivação, emoção, punição e esquiva. Nós analisamos demonstrações, discutimos procedimentos de instrução e consideramos problemas de publicação. Nat e eu descrevemos nosso curso básico e contamos sobre os cursos que estávamos iniciando no outono: ofertas de laboratório em motivação e discriminação, um curso em psicologia social e anormal, a ser lecionado por Ralph (Otto estava mudando para um novo departamento); e dois seminários avançados, os quais nós três frequentaríamos. Todos participaram de modo informal e a reunião foi considerada um grande sucesso [ênfase adicionada]. Decidimos fazer uma gravação da mesma (notas da conferência sobre a análise experimental do comportamento, 1947) para referências posteriores. (Keller, 2009, p. 200)

Um dos produtos desse evento, que represen- ta seu papel na organização social da área, foi a criação de um boletim informativo para manter os participantes da conferência em contato, sendo o próprio Skinner responsável pela organização do primeiro número dessa publicação. Para Dinsmoor (1987), a conferência de 1947 pode ser vista como a precursora de organizações como a Sociedade de Análise Experimental do Comportamento (SEAB), a Divisão 25 da Associação Americana de Psicologia (APA) e a Associação de Análise do Comportamento (ABA). Já o boletim poderia ser considerado o predecessor do Journal of Experimental Analysis of Behavior (JEAB).

Esse boletim, composto por notas mimeografadas, teve como propósito, de acordo com Skinner (1984), manter os participantes da conferência em contato. Porém, do mesmo modo que a programação da conferência, seu conteúdo extrapolou essa função e serviu de meio para a transmissão das definições básicas de uma nova ciência do comportamento.

Abaixo, registra-se a introdução do primeiro número desse boletim informativo, elaborado por Skinner e enviado aos participantes da primeira conferência de análise experimental do comportamento, no qual, mais uma vez, sobressai a informalidade do encontro que originou essa publicação.

$\mathrm{Na}$ última reunião da conferência, em Bloomington, em junho de 1947, um forte sentimento foi expresso por um tipo de publicação informal que tornaria possível continuar, ao longo do ano, o intercâmbio de ideias e dados que começou nas reuniões [ênfase adicionada]. Os periódicos mostravam-se lentos demais e, de qualquer modo, não publicariam os relatórios preliminares, os relatórios dos experimentos-piloto, as teorias experimentais de fórmulas ou sugestões, que foram consideradas de grande valor. Foi, portanto, planejada a emissão de uma série de notas mimeografadas em páginas da Universidade de Indiana para membros da Conferência e outros interessados. (Dinsmoor, 1987, p. 445)

Neste boletim é apresentada uma breve discussão sobre as diferenças entre os conceitos de punição, reforço positivo, reforço negativo, fuga e esquiva - alguns dos conceitos básicos do sistema explicativo Skinneriano que teriam produzido, de acordo com Skinner (1979), dúvidas comuns entre 
aqueles que entravam em contato pela primeira vez com as definições de reforço e punição.

A propagação de inúmeras estratégias de difusão da área é visível a partir deste momento. A publicação de distintas obras que servem à disciplinarização da área, como o já citado livro texto de Keller e Schoenfeld (1950), e as contínuas realizações de outras conferências de análise experimental do comportamento, que se tornaram parte de outros encontros científicos de maior porte, denotam a expansão do campo entre as décadas de 1950 e 1960.

A partir de 1956, por exemplo, a conferência de análise experimental do comportamento começa a ser parte do encontro anual da APA. Mas, para Skinner (1979), aquilo que à primeira vista parecia ser um benefício para a análise do comportamento logo transformou-se em fonte de problemas. A falta de espaços e de horários para realização da conferência nos encontros da APA foram os primeiros deles. Durante a década de 1950, houve um aumento constante do número de participantes nas conferências, o que acarretou a necessidade de mais espaço e de horários adicionais para a sua realização. Contudo, essas alterações não aconteciam de maneira adequada e inúmeras dificuldades começaram a surgir (Skinner, 1979).

Por exemplo, no encontro da APA de 1960, Skinner (1979) lembra que eram necessárias de três a quatro sessões de meio período, as quais dependiam da "generosidade" (p. 87) da divisão de psicologia experimental da APA - o que não ocorreu. $O$ resultado desse tipo de dificuldade era sempre a alocação dos participantes da conferência em salas pequenas, com pouca ventilação e que rapidamente ficavam lotadas (Skinner, 1979). Por isso, costumava ser necessário procurar salas maiores, o que levava à desorganização da conferência e, por conseguinte, a "inconvenientes e a tempo perdido" ( $p$. 262). A fim de resolver esse problema, os editores do recém-lançado JEAB criaram um comitê para formalizar uma divisão separada de análise experimental do comportamento. Conforme Skinner (1984), a medida foi facilmente aceita pela APA.

Ao avaliar esse momento de expansão e formalização da disciplina, Skinner (1984) se interroga sobre as vantagens de estar associado à APA. Além dos problemas já apontados, esse questionamento se dá porque, segundo Skinner, em encontros deste tipo os trabalhos dos analistas do comportamento eram misturados a outros trabalhos que raramente lhe despertavam algum interesse. Tal insatisfação manifesta-se no início da década de 1960, quando, ao rejeitar a proposta de candidatura ao cargo de presidente da APA, Skinner apresenta entre suas justificativas a seguinte alegação: "Eu estava interessado em nada mais que cinco por cento das atividades da Associação e não tinha nenhuma inclinação para me tornar familiar com os outros noventa e cinco por cento" (Skinner, 1984, p. 287). Na verdade, mesmo celebrando a expansão de sua ciência, Skinner (1984) chega a dizer que o custo da crescente difusão da área o fazia pensar que a informalidade tinha suas vantagens.

\section{Considerações Finais}

No presente trabalho, expomos uma possibilidade interpretativa inicial da constituição histórica da análise do comportamento, a partir de elementos tradicionalmente descartados na história de uma ciência. Nesse caso, enfatizamos o caráter informal que perpassou a organização social dessa ciência. Ademais, argumentamos que a rejeição inicial do delineamento experimental de sujeito único foi fator determinante para que os primeiros analistas do comportamento elaborassem estratégias de organização social da ciência.

Identificamos também que as relações informais - marca da organização inicial dessa nova comunidade científica - estiveram presentes desde o período inicial de formulação do sistema científico Skinneriano, entre o final da década de 1920 e o final da década de 1930, conforme indica o intenso contato entre Skinner e Keller. Contato esse que permitiu a troca de informações científicas e a implantação de práticas institucionais que levaram, entre outras coisas, a tornar Keller o principal divulgador da análise do comportamento e seu primeiro adepto. Dito isso, também argumentamos que o contato entre esses dois psicólogos seria o embrião da organização social da análise do comportamento, visível somente a partir de meados da década de 1940 - período no qual os primeiros interessados em realizar pesquisas que recorriam ao delineamento experimental de sujeito único sofreram dificuldades de aceitação desse método no contexto da psicologia experimental norte-americana.

Eis o começo da transformação de um gru- 
po organizado de forma quase informal para uma crescente organização formal da ciência, observada no desenvolvimento da análise do comportamento enquanto uma nova comunidade científica. Em outros termos, uma transição da informalidade para a formalidade da ciência. Em 1947, a realização da primeira conferência de análise experimental representaria o primeiro esforço declarado para enfrentar os problemas de isolamento e rejeição dessa nova ciência, os quais poderiam ser amenizados a partir da formação de um grupo inicial de praticantes dessa ciência. Mas, como exposto, o objetivo desse evento ultrapassou esses fatores e se constituiu como um espaço inicial de definição e de disseminação daquele novo campo do conhecimento. Não por acaso, questões relativas à identidade dos primeiros praticantes dessa ciência e aos meios de divulgação científica surgiram nos relatos dos participantes da conferência. Ademais, também não é coincidência a existência de um esforço para apresentar as definições básicas da análise experimental do comportamento, procedimento comum em momentos de instauração de uma nova comunidade científica (Kuhn, 1962/2006).

Obviamente, apesar de não termos tratado destes aspectos no presente trabalho, a propagação e a crescente formalização da análise do comportamento não podem ser restritas à realização da primeira conferência. A criação de um currículo de psicologia fundamentado na análise experimental do comportamento (Keller \& Schoenfeld, 1949), a publicação do primeiro livro-texto (Keller \& Schoenfeld, 1949), a realização de outros eventos da área, entre outros diversos empreendimentos envolvendo a divulgação e organização social da análise do comportamento, sinalizam sua expansão a partir de meados da década de 1940 e devem ser vistos como fontes de análise da história dessa ciência.

Ao mesmo tempo, ainda que não tenhamos nos aprofundado nestas questões, é necessário notar que a contínua expansão da análise do comportamento não representou a diminuição de sua rejeição no cenário da psicologia experimental norte-americana. Problema esse notado a partir das décadas de 1950 e de 1960, quando inúmeras críticas dirigidas à análise do comportamento - enquanto uma comunidade científica ortodoxa e com pouca abertura para o diálogo com outras perspectivas serão observadas na literatura tanto interna quanto externa ao campo (Krantz, 1971, 1972). Algo que teria se perpetuado até os dias atuais, quando se percebe que a linguagem da área continua acessível quase que exclusivamente apenas a seus praticantes e que suas publicações e eventos continuam impermeáveis a teorias, metodologias e debates não definidos pela área. A hipótese de que a análise do comportamento estaria atualmente tão isolada quanto a quatro décadas atrás seria assim levantada por alguns autores (Coleman \& Mehlman, 1992; Rutherford, 2009). Este problema, aliás, está sendo tratado em outro trabalho já em andamento.

Por último, salienta-se que, embora a ênfase adotada neste estudo tenha diminuído naturalmente o recurso a informações de ordem científica, isso não significou considerar essas informações como sendo de menor valor e muito menos incompatíveis com a presente análise. Na realidade, esse estudo apresenta-se, mesmo que de forma incipiente, como um complemento a investigações conceituais da análise do comportamento. Tal complementariedade evitaria tratar a história dessa ciência como independente dos comportamentos sociais envolvidos na sua constituição. Comportamentos esses que muitas vezes ultrapassam o espaço do laboratório e da construção lógica da ciência e que, por isso, são muitas vezes apagados ou percebidos como parte de uma história dos bastidores da ciência, que nada teria a ver com os determinantes de sua situação atual. Dito isso, conclui-se também que a observação de uma crescente formalidade na história da análise do comportamento, em suas primeiras décadas, não significa a extinção da informalidade como parte constituinte de sua organização social. Em outras palavras, a informalidade na ciência nunca deixa de existir e afetar, em alguma medida, seus rumos.

\section{Referências}

Bjork, D. W. (1993). B. F. Skinner: A life. New York: Sheridan Books.

Chiesa, M. (1994). Radical behaviorism: The philosophy and the science. Boston: Authors Cooperative.

Coleman, S. R., \& Mehlman, S. E. (1992). An empirical uptade (1969-1989) of D. L. Krantz's thesis that the experimental analysis of behavior is isolated. The Behavior Analyst, 15(1), 43-49. Crane, D. (1972). Invisible colleges. Chicago: 
University of Chicago Press.

Cruz, R. N. (2010). Possíveis relações entre o contexto histórico e a recepção do behaviorismo radical. Psicologia: Ciência e Profissão, 30(3), 478-491.

Cruz, R. N. (2011). Percalços na história da ciência: B. F. Skinner e a recepção inicial da análise experimental do comportamento entre as décadas de 1930 e 1940. Psicologia: Teoria \& Pesquisa, 27(4), 401-415.

Dews, P. B. (1987). An outsider on the inside. Journal of the Experimental Analysis of Behavior, 48(3), 459-462.

Dinsmoor, J. A. (1987). A visit to Bloomington: The first conference on the experimental analysis of behavior. Journal of the Experimental Analysis of Behavior, 48(3), 441-445.

Harlow, H. F. (1951). Publication policy for The Journal of Comparative Physiological Psychology. The Journal of Comparative Physiological Psychology, 44(1), 1-2.

Kelleher, R. T., \& Morse, W. H. (1987). The Yerkes connection. Journal of the Experimental Analysis of Behavior, 48(3), 456-457.

Keller, F. S. (2009). At my own pace: The autobiography of Fred S. Keller. New York: Sloan Publishing.

Keller, F. S., \& Schoenfeld, W. N. (1949). The psychology curriculum at Columbia College. American Psychologist, 4(6), 165-172.

Keller, F. S., \& Schoenfeld, W. N. (1950). Principles of psychology: a systematic text in the science of behavior. New York: Appleton-Century-Crofts

Krantz, D. L. (1971). The separate worlds of operant and non-operant psychology. Journal of Applied Behavioral Analysis, 4(1), 61-70.

Krantz, D. L. (1972). Schools and systems: The mutual isolation of operant and non-operant psychology as a case study. Journal of the History of the Behavioral Sciences, 8(1), 86-102.

Kuhn, T. S. (2006). A estrutura das revoluções científicas. São Paulo. Coleção Debates - ciência. EditoraBroch. (Trabalho original publicado em 1962)

Laties, V. G. (1987). Society for the Experimental Analysis of Behavior: The first 30 years (19581987). Journal of the Experimental Analysis of Behavior, 48(3), 495-512.
Lindsley, O. L. (1987). Collecting the first dollars for JEAB. Journal of the Experimental Analysis of Behavior, 48(3), 469-471.

Meadows, A. J. (1999). A comunicação científica. Brasília: Briquet de Lemos.

Menzel, H. (1966). Scientific communication: fives themes from social science research. American Psychologist, 21(11), 999-1004.

Price, D. S. (1976). O desenvolvimento da ciência: Análise histórica, filosófica, sociológica e econômica (Simão Mathias, Trad.). Rio de Janeiro: Livros Técnicos e Científicos.

Price, D.S. e Beaver, D. (1966). Colaboration in an invisible college. American Psychologist, 21 (11), 1011-1017.

Rossi, P. (1989). Os filósofos e as máquinas: 14001700 (Federico Carotti, Trad.). São Paulo: Companhia das Letras.

Rossi, P. (2001). O nascimento da ciência moderna na Europa. (A. Angonese, Trad.). Bauru: EDUSP.

Rucci, A. J., \& Tweney, R. D. (1980). Analysis of variance and the "second discipline" of scientific psychology. Psychological Bulletin, 87(1), 166-184.

Rutherford, A. (2000). Radical behaviorism and psychology's public: B. F. Skinner in the popular press, 1934-1990. History of Psychology, 3(4), 371-395.

Rutherford, A. (2003). B. F. Skinner's technology of behavior in American life: From consumer culture to counter culture. Journal of History of the Behavioral Sciences, 39(1), 1-23.

Rutherford, A. (2004). A "visible scientist": B. F. Skinner writes for the popular press. The European Journal of Behavior Analysis, 5(2), 109-120.

Rutherford, A. (2009). Beyond the Box: B. F. Skinner's Technology of Behavior from Laboratory to life, 1950-1970s. Toronto: University of Toronto Press.

Shapin, S., \& Schaffer, S. (1985). Leviathan and the air-pump: Hobbes, Boyle and the experimental life. Princenton: Princenton University Press.

Skinner, B. F. (1938). The Behavior of Organisms: An experimental analysis. New York: AppletonCentury.

Skinner, B. F. (1945). The operational analysis of 
psychological terms. Psychological Review, 52, 270-277.

Skinner, B. F. (1979). The shaping of a behaviorist: Part two of an autobiography. New York: Alfred A. Knopf.

Skinner, B. F. (1984). A matter of consequences: Part three of an autobiography. New York University Press.

Swanson, D.R. (1966). Scientific journals and information services of the future. American Psychologist, 21(11), 1005-1010.

\section{Agradecimento}

O autor agradece os comentários realizados pelo professor Kester Carrara, da Universidade Estadual Paulista, e pela mestranda Luciana Maria de Souza, do Departamento de Psicologia da Universidade Federal de Minas Gerais. O autor também agradece a leitura cuidadosa e os comentários didáticos tecidos pelos pareceristas anônimos da revista Perspectivas em Análise do Comportamento. Ainda assim, admite a responsabilidade integral por eventuais erros e omissões.

\section{Informações do artigo}

\section{História do artigo}

Data de submissão em: 29/07/2011

Primeira decisão editorial em: 02/09/2011

Aceito para publicação em: 04/11/2011 